OPEN ACCESS

Edited by:

Masahiro Tsuji,

National Cerebral and Cardiovascular

Center, Japan

Reviewed by:

Masanori Iwai,

Kumamoto University Hospital, Japan

Tina Bregant,

Children's Hospital Ljubljana,

Slovenia

${ }^{*}$ Correspondence:

Lauren L. Jantzie

ljantzie@salud.unm.edu;

Shenandoah Robinson

srobin81@jhmi.edu

Specialty section:

This article was submitted to

Pediatric Neurology,

a section of the journal

Frontiers in Neurology

Received: 09 December 2017

Accepted: 26 March 2018

Published: 13 April 2018

Citation:

Jantzie LL, Oppong AY, Conteh FS, Yellowhair TR, Kim J, Fink G, Wolin AR, Northington FJ and Robinson S (2018) Repetitive Neonatal Erythropoietin and Melatonin Combinatorial Treatment

Provides Sustained Repair of

Functional Deficits in a Rat

Model of Cerebral Palsy.

Front. Neurol. 9:233.

doi: 10.3389/fneur.2018.00233

\section{Repetitive Neonatal Erythropoietin and Melatonin Combinatorial Treatment Provides Sustained Repair of Functional Deficits in a Rat Model of Cerebral Palsy}

\author{
Lauren L. Jantzie ${ }^{1,2 *}$, Akosua Y. Oppong ${ }^{3}$, Fatu S. Conteh ${ }^{3}$, Tracylyn R. Yellowhair ${ }^{1}$, \\ Joshua Kim ${ }^{3}$, Gabrielle Fink ${ }^{3}$, Adam R. Wolin ${ }^{3}$, Frances J. Northington ${ }^{4}$ and \\ Shenandoah Robinson ${ }^{3 *}$
}

${ }^{1}$ Department of Pediatrics, University of New Mexico School of Medicine, University of New Mexico, Albuquerque, NM, United States, ${ }^{2}$ Department of Neurosciences, University of New Mexico School of Medicine, University of New Mexico, Albuquerque, NM, United States, ${ }^{3}$ Pediatric Neurosurgery, Johns Hopkins University, Baltimore, MD, United States, ${ }^{4}$ Neonatology, Department of Pediatrics, Johns Hopkins School of Medicine, Baltimore, MD, United States

Cerebral palsy (CP) is the leading cause of motor impairment for children worldwide and results from perinatal brain injury (PBI). To test novel therapeutics to mitigate deficits from $\mathrm{PBI}$, we developed a rat model of extreme preterm birth ( $<28$ weeks of gestation) that mimics dual intrauterine injury from placental underperfusion and chorioamnionitis. We hypothesized that a sustained postnatal treatment regimen that combines the endogenous neuroreparative agents erythropoietin (EPO) and melatonin (MLT) would mitigate molecular, sensorimotor, and cognitive abnormalities in adults rats following prenatal injury. On embryonic day 18 (E18), a laparotomy was performed in pregnant SpragueDawley rats. Uterine artery occlusion was performed for $60 \mathrm{~min}$ to induce placental insufficiency via transient systemic hypoxia-ischemia, followed by intra-amniotic injections of lipopolysaccharide, and laparotomy closure. On postnatal day 1 (P1), approximately equivalent to 30 weeks of gestation, injured rats were randomized to an extended $\mathrm{EPO}+\mathrm{MLT}$ treatment regimen, or vehicle (sterile saline) from P1 to P10. Behavioral assays were performed along an extended developmental time course $(n=6-29)$. Open field testing shows injured rats exhibit hypermobility and disinhibition and that combined neonatal EPO + MLT treatment repairs disinhibition in injured rats, while EPO alone does not. Furthermore, EPO + MLT normalizes hindlimb deficits, including reduced paw area and paw pressure at peak stance, and elevated percent shared stance after prenatal injury. Injured rats had fewer social interactions than shams, and EPO + MLT normalized social drive. Touchscreen operant chamber testing of visual discrimination and reversal shows that EPO + MLT at least partially normalizes theses complex cognitive tasks. Together, these data indicate EPO + MLT can potentially repair multiple sensorimotor, cognitive, and behavioral realms following PBI, using highly translatable and sophisticated developmental testing platforms.

Keywords: cerebral palsy, chorioamnionitis, hypoxia-ischemia, inflammation, social interaction, gait, touchscreen, cognition 


\section{INTRODUCTION}

Cerebral palsy (CP) is the leading cause of motor impairment for children worldwide and typically results from perinatal brain injury (PBI) $(1,2)$. While preterm birth is a common etiologic antecedent, motor impairment and associated deficits can also arise from other insults to the developing central nervous system (CNS), including trauma and stroke. Notably, the scope of PBI has shifted over recent decades as more preterm infants survive (3-5), and the proportion of children with more severe motor impairment has increased in the USA (6). Within subpopulations of neonates with PBI, multiple injury mechanisms have been implicated, and emerging evidence strongly suggests that each newborn suffers a unique vulnerability to CNS injury from a combination of (1) inflammation from prenatal infection and/or hypoxia-ischemia (HI); (2) individualized risk from genetic and/ or congenital predisposition and acquired prenatal exposures to drugs, toxins, and nutritional status; and (3) postnatal stresses, such as sepsis and surgery. Indeed, intrapartum events are implicated in the etiology of less than $12 \%$ of children with CP (7). Thus, there is an urgent need for safe, effective interventions for $\mathrm{PBI}$, and subsequent $\mathrm{CP}$ and related deficits.

Infection and HI catalyze PBI by creating a toxic in utero and neural microenvironment that limits oxygen exchange and propagates inflammation during critical periods of neurodevelopment (8-15). Typically, infants with PBI present with injury to major white and gray matter structures that leads to reduced connectivity of developing cerebral networks. Subsequently, diverse functional deficits ensue with impairment in multiple motor, cognitive, and behavioral realms that precipitates poor educational progress during childhood (16-25). Chorioamnionitis (infection/inflammation of the amniotic fluid, membranes, and placenta) affects placental permeability and blood flow, facilitates HI and fetal transmission of inflammation, and is associated with a significant increase in systemic inflammation (26-29). Chorioamnionitis is common in both preterm and term infants $(23,24,29-34)$. It affects approximately $40-80 \%$ of very preterm deliveries and $20-34 \%$ of deliveries at term $(30,33,35)$. Chorioamnionitis is also recognized in as many as $42 \%$ of placentas from unremarkable pregnancies $(29,36)$. Notably, in term infants with $\mathrm{HI}$ encephalopathy, the presence of chorioamnionitis predicts decreased responsiveness to hypothermia treatment $(8-10,30-32,37,38)$ and magnesium sulfate (39). Because these current strategies for neonatal repair are less effective in the setting of chorioamnionitis, we sought to address this unmet need by testing promising neuroreparative agents using a preclinical model of chorioamnionitis.

Despite the wealth of epidemiological and clinical data related to chorioamnionitis and the development of motor deficits in children born preterm, little progress has been made in identifying interventions that mitigate the CNS injury that leads to CP. Indeed, ambulation, behavior, and cognition are complex tasks impacted by early CNS injury (40). To minimize deficits and optimize outcomes for children with CP, novel therapies are required to restore motor skills, sensation, behavior such as attention and social interaction, and cognition, including executive function. However, few novel therapies have directly addressed these complex and compound deficits, particularly the functional pillars of cognition and behavior with motor impairment. Here, we studied a combination therapy of the endogenous neuroreparative agents erythropoietin (EPO) and melatonin (MLT) in an established preclinical rat model that accurately encompasses the complete maternal-placental-fetal brain axis with intrauterine injury and recapitulates pathophysiology from extreme preterm birth. We chose a cocktail strategy to mitigate the multiple pathophysiological mechanisms that contribute to PBI, capitalize on innate CNS recovery, and respond to clinical recommendations on utility of single therapies (41-43). Furthermore, data from our labs and others, confirm combinatorial therapy with EPO + MLT may provide enhanced, synergistic neurorepair by (1) optimizing the genesis and survival of multiple neural cell lineages, including cells with high bioenergetic demands, such as oligodendrocytes, myelin sheaths, and ependyma with motile cilia, (2) normalizing excess calpain activity and its destruction of essential molecules during neurodevelopment, (3) reducing neuroinflammation and free radicals, and (4) limiting mitochondrial dysfunction and associated endoplasmic reticulum stress (44-55). Given this unique avenue for translation and targeted mechanisms of action, we tested the hypothesis that an extended postnatal EPO + MLT cocktail would mitigate gait, sensorimotor, cognitive, and behavioral changes associated with PBI, using highly translatable and sophisticated testing platforms that are similar to the ones used in humans, including digital gait analysis and touchscreen cognitive testing.

\section{MATERIALS AND METHODS}

The Institutional Care and Use Committee at the University of New Mexico Health Sciences Center, Boston Children's Hospital and Johns Hopkins University approved all experimental procedures. For each experiment described, equal numbers of male and female pups were used, and data represents true $n$ (individual pups) from at least two different dams per condition. Specifically, we adhered to accepted standards for rigorous study design and reporting to maximize the reproducibility and translational potential of our findings, as described by Landis et al. and in the ARRIVE guidelines (56-58). Animals of both sexes were randomized to experimental or sham control groups and EPO + MLT or vehicle treatments. All investigators were blinded to injury and treatment group during the conduct and analyses of each experiment. For each experiment, a power analysis was also performed to estimate the required sample size ( $\mathrm{G}^{*}$ Power 3.1.9.3). For these calculations, we used published and preliminary data to define the expected means and SDs for each group, and we exceeded the calculated number needed in every experiment. Separate cohorts of rats were used for open field, gait and social interaction, and touchscreen assessments.

\section{In Utero Injury: Chorioamnionitis}

As placental structure and function is of significant clinical importance to neurologic sequelae in preterm survivors (59-61), we use a prenatal model of in utero transient systemic HI (TSHI) and intra-amniotic lipopolysaccharide (LPS) administration in pregnant rats (62-64). This approach capitalizes on an intact 
maternal-placental-fetal unit and is a model of PBI from extreme preterm birth ( $<28$ weeks of gestation) that mimics dual intrauterine injury from placental underperfusion and chorioamnionitis (65). Briefly, under isoflurane anesthesia, a laparotomy is performed on embryonic day (E) 18. Uterine arteries are clamped for $60 \mathrm{~min}$ and followed by intra-amniotic injections of LPS ( $4 \mu \mathrm{g} / \mathrm{sac}$; 0111:B4, Sigma, St. Louis, MO, USA) $(62,64,65)$. Sham controls undergo anesthesia and laparotomy for 60 min without arterial clamping or LPS injections. Following closure of the laparotomy, dams receive narcotic pain medication, recover, and pups are born vaginally at E22, approximately equal to 30-32 weeks in human gestation. We have previously reported the effects of TSHI and LPS alone, and in concert, on CNS pathological hallmarks, functional motor outcomes, histologic placental injury, and expression of common pro-inflammatory cytokines $(63,64)$.

\section{EPO and MLT Combination Therapy}

Erythropoietin and MLT are endogenous, developmentally regulated molecules that are individually most effective for neurorepair when administered in extended dosing regimens $(45,48$, 66-69). Rodents are born at a time equivalent to the human third trimester, with P9 approximately equivalent to term in human gestation (70). Accordingly, we used an established, clinically relevant dosing regimen $(47,48,55,71)$, in which pups on postnatal day $(\mathrm{P}) 1$ from all injured litters were individually randomized to receive either EPO (2,000 U/kg, R\&D Systems, Minneapolis, MN, USA) plus MLT (20 mg/kg, Sigma), or vehicle (sterile saline). Subsequently, EPO was then administered intraperitoneally once daily from P1 to P5 and MLT was administered once daily from P1 to P10, comparable to dosing regimens used in human neonatal trials. When EPO was administered in isolation, it was given from $\mathrm{P} 1$ to $\mathrm{P} 5$ at $2,000 \mathrm{U} / \mathrm{kg} / \mathrm{dose}$ as previously published $(47,48,54,55,71,72)$. Prior work has shown that shams do not exhibit any negative effects from EPO and MLT treatment (55), and thus to conserve resources, shams received only vehicle.

\section{Open Field}

A circular open field arena (100 cm diameter) was placed in a quiet, well-lit room $(130 \mathrm{~lm})$, and was marked to divide the arena into three equally spaced, concentric circles labeled the center, neutral, and peripheral zones. At P28-P30, each rat was initially placed against the wall of the testing arena and allowed to explore for $15 \mathrm{~min}$. Anymaze ${ }^{\mathrm{TM}}$ video-tracking software was used to record and measure open field behavior.

\section{Gait Analysis}

Computerized gait analysis was performed on P25-P26 as previously described $(62,71)$. Briefly, digital video of each rat running on a backlit transparent treadmill set at $30 \mathrm{~cm} / \mathrm{s}$ was acquired with a high-speed camera and analyzed using Digigait software (Mouse Specifics, Framingham, MA, USA). Digigait software analyses identifies individual paw prints and allows calculation of multiple gait metrics and kinematic measurements based on the position, area, and timing of each step. In utero chorioamnionitis induces a global injury. Thus, data from right and left hindlimbs were combined for analysis.

\section{Social Interaction}

A standard paradigm was used to identify impaired social interaction in rats at P30-P32 (73-75). Briefly, $1 \mathrm{~h}$ prior to testing, each rat was isolated in a clean cage. For social interaction testing, two rats of the same sex and treatment group, but from different litters, were placed in a dimly lit $(30 \mathrm{~lm})$ circular testing arena ( $100 \mathrm{~cm}$ diameter) and recorded for $10 \mathrm{~min}$ using Anymaze $^{\mathrm{TM}}$ video-tracking software. Each pair was counted as one social unit. Two observers blinded to the treatment group independently reviewed the trials and scored periods of social interaction (trailing, sniffing, grooming, playing, etc.). Intraclass coefficient was calculated for interrater reliability of social scoring. Olfactory testing for social and food odors confirmed primary sensory deficits were not related to the impaired social interaction observed in the injured animals.

\section{Touchscreen Testing}

To better define deficits in cognitive realms, we use a touchscreen operant platform to test specific components of cognition and executive function commencing with mild food deprivation at $\mathrm{P} 28$, training at $\mathrm{P} 35$, initial testing at $\mathrm{P} 42$, and continuing through completion of the paradigms at approximately P90 (76-80). Briefly, using a separate cohort of rats, operant behavior was tested in a sound and light attenuating chamber (Med Associates, St. Albans, VT, USA). A pellet dispenser delivers $40 \mathrm{mg}$ dustless pellets (Bioserv, Frenchtown, NJ, USA) into a magazine, and a houselight is located at one end of the chamber. The opposite end of the chamber houses a touch-sensitive screen (Conclusive Solutions, Sawbridgeworth, UK) overlaid by a black acrylic aperture plate, resulting in two separate touch areas for the rat to register a response. Stimulus presentation in the response windows and touches were controlled and recorded by KLimbic Software (Conclusive Solutions).

\section{Pretraining}

On P28, rats were first slowly reduced and then maintained at $85 \%$ free-feeding body weight. Rats were weighed and assessed for general health daily. The mild weight reduction was well tolerated. Prior to training, rats were acclimated to the $40 \mathrm{mg}$ food pellet reward by provision of 25 pellets/rat in the home cage. Rats were then habituated to the operant chamber and to eating from the pellet magazine. Rats retrieving at least 48 pellets in $60 \mathrm{~min}$ were moved to a 4 -stage training regimen. Rats first performed autoshaping, followed by three visual discrimination training sessions (76-79).

\section{Discrimination and Reversal Learning}

Following pretraining, all rats were tested on a pairwise discrimination-reversal paradigm during daily $60 \mathrm{~min}$ sessions. For discrimination learning, 2 novel, equiluminescent stimuli verified for rats, were presented in a spatially pseudo-randomized manner over 60-trial sessions (5-s inter-trial interval) (76-80). Responses at one stimulus yielded a reward, whereas responses at the other stimulus resulted in a $5 \mathrm{~s}$ time-out (singled by extinguishing the house light). Designation of initially reward stimulus was randomized across treatment. Stimuli remained on screen until a response was made. Rats were trained to an a priori criterion 
of greater than $\geq 80 \%$ correct responses for two consecutive days. Assessment of reversal learning began on the session after discrimination criterion was attained. For this test, the designation of stimuli as correct versus incorrect was reversed for each rat. Like discrimination, rats were tested on 60-trial daily sessions for reversal to an a priori criterion of $\geq 80 \%$ correct responses for two consecutive sessions. Errors on first presentation reversal trials were followed by correction trials which continued until a correct response was made, or the session ended. Failing criteria was set $a$ priori at 21 sessions (days) for visual discrimination and 21 sessions (days) for reversal.

We recorded the following dependent measures during discrimination and reversal: total sessions, correct responses made, errors (incorrect responses made), correction errors (correction trials, reversal only), reaction time (time from stimulus presentation to touchscreen response), and magazine latency (time from touchscreen response to reward retrieval) (81). Discrimination performance was analyzed across all sessions required to reach criterion. To examine distinct phases of reversal (early perseverative and late learning) mediated by cortical and striatal subregions, respectively, we also analyzed errors and correction trials. Assuming a rat would achieve $50 \%$ correct by chance, perseveration was defined as sessions where performance was below $50 \%$ correct, and learning as performance from 50\% correct to passing criterion, as previously described (81-83).

\section{Statistical Analysis}

Statistical analyses were performed using SPSS25 (IBM, Armonk, NY, USA). For all analyses, data are represented as mean \pm SEM, with $p<0.05$ considered significant. For analysis of sham, vehicle-treated injury and EPO + MLT-treated injury groups, all parametric variables were tested for normal distribution with the Shapiro-Wilk test with Levene's test to confirm homogeneity of variances. A two-way ANOVA was then performed with Bonferroni's post hoc correction for multiple comparisons. For non-parametric variables such as passing criteria in touchscreen testing, a Kruskal-Wallis test with Dunn's post hoc correction was performed.

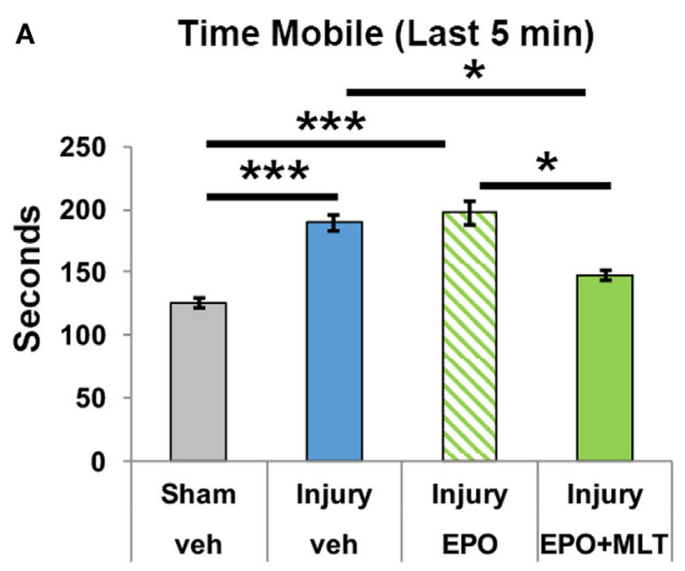

\section{B Total Time Immobile in Center}
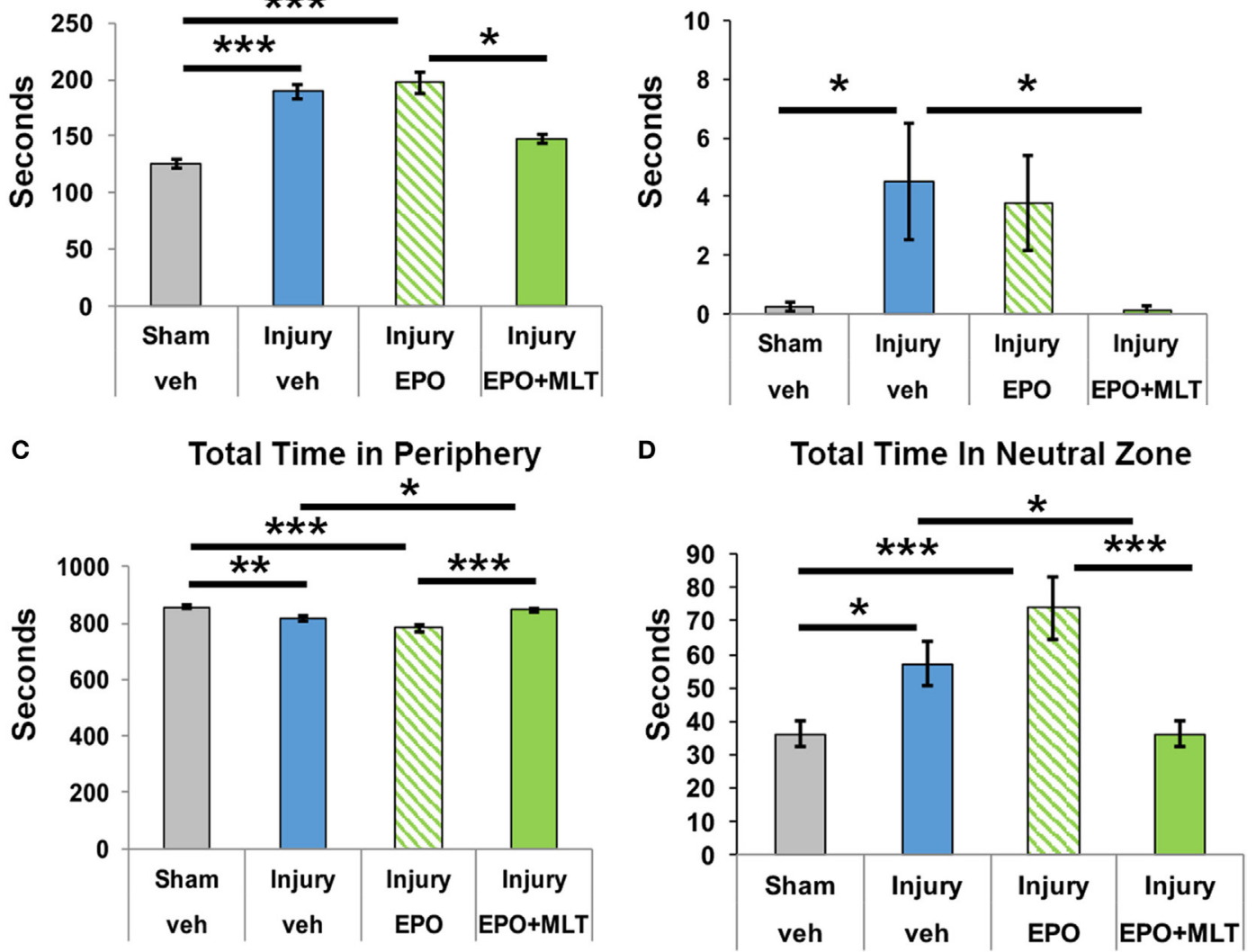

FIGURE 1 | Open field testing of locomotion and disinhibition. (A) After prenatal injury, vehicle-treated rats are more mobile than shams, particularly in the last 5 min interval. Erythropoietin (EPO) + melatonin (MLT), but not EPO alone, normalizes the activity. (B) Rats typically avoid open areas. Vehicle-treated adult rats following prenatal injury spend more time immobile in the center zone than sham rats or EPO + MLT-treated rats. (C) Sham and EPO + MLT-treated injured rats spent more time in the peripheral zone than vehicle-treated or EPO-treated injured rats. (D) Similarly, vehicle-treated injured rats spent more time in the neutral zone than sham or EPO + MLT-treated rats. EPO treatment by itself did not improve disinhibition (two-way ANOVA with Bonferroni correction, ${ }^{*} p<0.05,{ }^{* \star} p<0.01,{ }^{* \star \star} p<0.001$ ). 

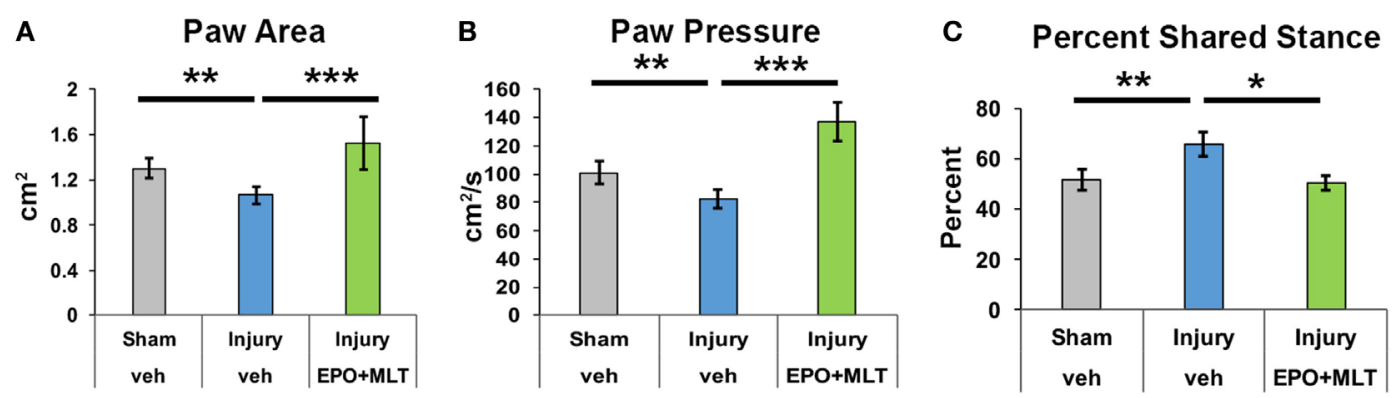

FIGURE 2 | Prenatal injury impairs gait performance. (A) After prenatal injury, vehicle-treated rats contact their hindpaws with less area than sham or erythropoietin $(E P O)+$ melatonin (MLT)-treated injured rats. (B) Similarly, vehicle-treated injured rats contact hindpaws with less pressure than shams or EPO + MLT-treated rats. (C) The percent of shared stance is elevated in vehicle-treated rats with prenatal injury compared to shams, and EPO + MLT treatment normalizes gait and posture (two-way ANOVA with Bonferroni correction, ${ }^{*} p<0.05,{ }^{* *} p<0.01,{ }^{* \star *} p<0.001$ ).

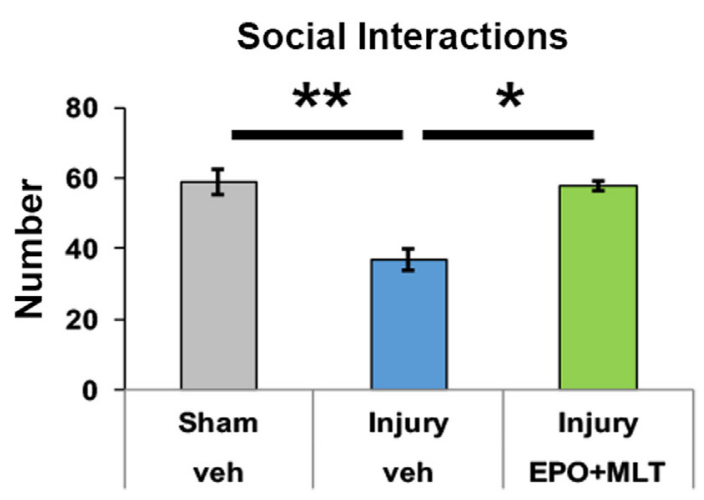

FIGURE 3 | Prenatal injury impairs social interaction. After prenatal injury, pairs of vehicle-treated rats of the same sex but different litters have fewer social interactions than pairs of shams, or pairs of erythropoietin (EPO) + melatonin (MLT)-treated injured rats (two-way ANOVA with Bonferroni correction, $\left.{ }^{\star} p<0.05,{ }^{\star \star} p<0.01\right)$.

\section{RESULTS}

\section{EPO + MLT Mitigates Disinhibition Following Prenatal Injury}

We assessed open field behavior to quantify activity and disinhibition. Compared to sham controls $(n=29)$, rats subjected to prenatal injury $(n=23)$ were much more mobile, which was particularly evident in the last $5 \mathrm{~min}$ of the 15 -min observation period (Figure 1A). Interestingly, compared to vehicle-treated rats with prenatal injury, EPO + MLT normalized the hypermobility $(n=28$, two-way ANOVA, $p=0.022)$, whereas EPO alone $(n=15)$ did not. After prenatal injury, adult rats were also disinhibited. Specifically, those with in utero injury showed a lack of environmental awareness by spending more time immobile in the arena center compared to shams ( $p=0.03$; Figure 1B). Similarly, prenatal injury had a significant effect on disinhibition, with sham rats exploring the peripheral zone for significantly longer periods compared to vehicle-treated injury rats $(p=0.001$; Figure 1C), and spending less time in the neutral zone ( $p=0.041$; Figure 1D). Treatment with EPO + MLT, but not EPO alone, normalized total time spent in the peripheral $(p=0.024)$ and neutral zones ( $p=0.038$; Figure 1), consistent with typical rat behavior, appropriate anxiety and general avoidance of open areas.

\section{EPO + MLT Normalizes Hindlimb Deficits After Prenatal Injury}

After observing that EPO + MLT normalized hyperlocomotion and disinhibition in adult rats following prenatal injury, we performed a detailed computerized digital analysis of gait to determine if EPO + MLT could improve motor performance. Compared to shams $(n=18)$, after prenatal injury vehicle-treated adult rats exhibit an abnormal gait, stance and paw placement, with decreased paw area contact $(n=21, p=0.012)$ and decreased paw pressure $(p=0.031)$ suggestive of toe-walking, and reduced percent shared stance $(n=21, p=0.006)$ (Figure 2) consistent with spastic gait patterns observed in ambulatory children with CP. Significantly, neonatal combination therapy with EPO + MLT $(n=7)$ reverses deficits in stance $(p=0.035)$ and paw placement (area and pressure both $p<0.001$ ), consistent with an improved gait kinematic efficiency with combination treatment.

\section{EPO + MLT Attenuates Deficits in Social Interaction}

To quantify social interaction, pairs of sex, injury, and treatmentmatched rats from different litters were observed and scored. The interrater reliability of social interaction scoring was 0.932 . Sham $(n=18$ rats in 9 pairs, $p<0.001)$ and injured rats treated with $\mathrm{EPO}+\operatorname{MLT}(n=8$ rats in 4 pairs, $p=0.007)$ had significantly more social interactions during the observation period, including sniffing, playing, and grooming, compared to vehicle-treated rats with in utero injury ( $n=14$ rats in 7 pairs) (Figure 3). Significantly, $\mathrm{EPO}+\mathrm{MLT}$ treatment ameliorated deficits in social drive and behavior.

\section{EPO + MLT Mitigates Deficits in Executive Function}

To complement our assessment of gait, open field, and social behavior in adult rats with in utero injury, we completed a sophisticated assessment of visual discrimination and reversal learning in our animals to evaluate executive function. We began by validating the touchscreen platform in our model of in utero 
chorioamnionitis and assessed whether adult rats following prenatal insult could perform visual discrimination. Importantly, rats in all three treatment groups were successful in completing all aspects of touchscreen habituation and training.

We first assessed cognitive performance on visual discrimination. Rats from each experimental group were able to perform VD, with $67 \%$ of sham $(n=27)$ and $20 \%$ of vehicle-treated injured rats $(n=20, p=0.005)$ achieving passing criteria, compared to $58.3 \%$ of injured rats treated with EPO $+\operatorname{MLT}(n=12, p=0.11$; Figure 4A). After assessing overall performance and pass rate, we then analyzed the number of errors throughout the visual discrimination paradigm as a more rigorous and granular metric of task performance. Notably, for those rats completing VD, a similar number of errors to achieve passing criteria was noted
A Passed Visual Discrimination

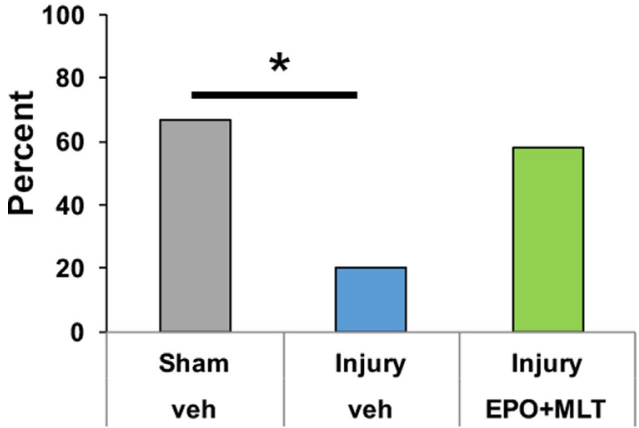

C

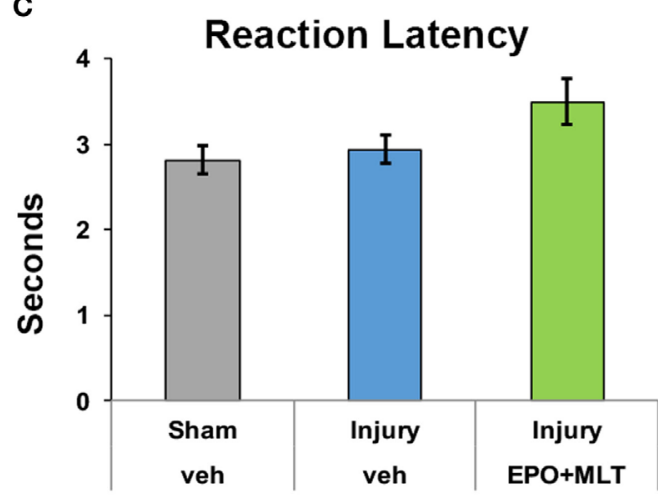

E

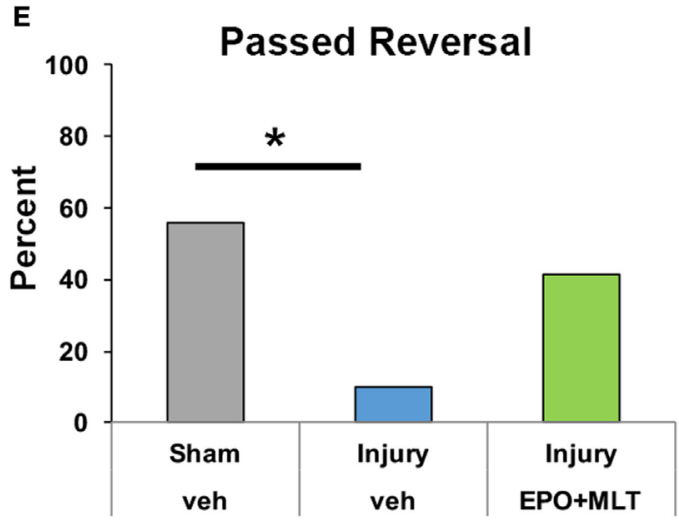

B

Errors to VD Criterion

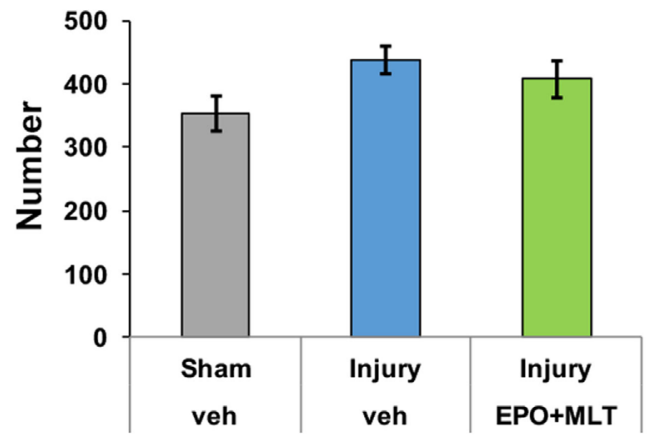

D

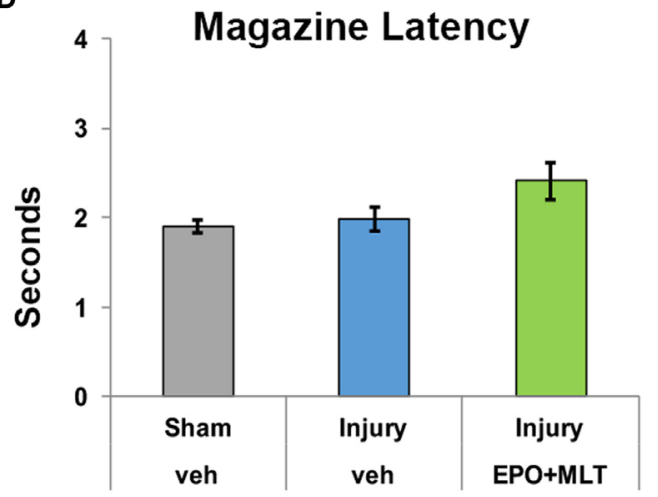

$\mathbf{F}$

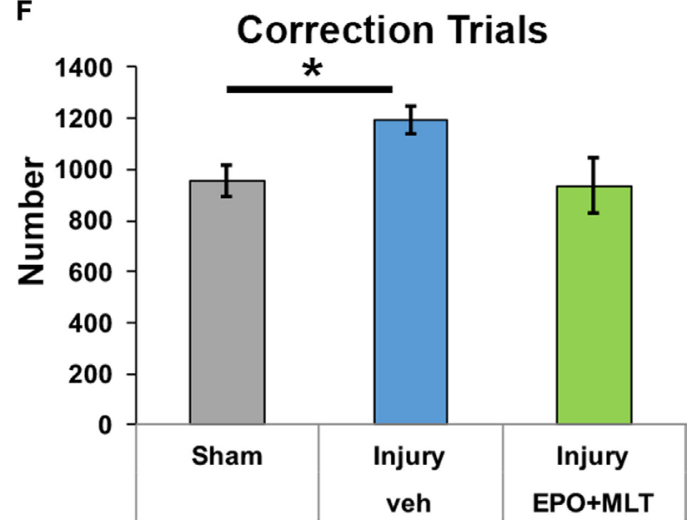

FIGURE 4 | Touchscreen operant chamber testing reveals impaired cognition. (A) Fewer vehicle-treated rats after prenatal injury successfully reached passing criterion for visual discrimination, compared to shams or erythropoietin (EPO) + melatonin (MLT)-treated injured rats $\left.{ }^{*} p<0.05\right)$. (B) Shams, vehicle-treated rats with prenatal injury, and EPO + MLT-treated rats with prenatal injury all committed approximately the same number of errors during visual discrimination testing. (C) The reaction latency between the three groups did not differ. (D) Likewise, the magazine latency was similar for all three groups. (E) Significantly fewer vehicle-treated rats after prenatal injury were able to pass criterion for VD and reversal $\left.{ }^{*} p<0.05\right)$. (F) After prenatal injury, vehicle-treated rats required more correction trials in reversal learning paradigms than shams. 
across injury and treatment groups (Figure 4B). As expected, all rats had comparable reaction time and magazine latency (Figures 4C,D) throughout the VD paradigm.

Upon successful completion of VD, rats were evaluated for reversal learning. Vehicle-treated injured rats were significantly impaired and fewer passed the overall learning paradigm compared to sham and EPO + MLT-treated rats. Specifically, only $10 \%$ of vehicle-treated injured animals successfully passed criteria for VD and reversal $(p=0.046)$ compared to $55.5 \%$ of sham and $41.5 \%$ of injured animals treated with EPO + MLT $(p=0.07$; Figure 4E). Notably, injured animals treated with vehicle required more correction trials compared to shams $(p=0.034)$. Injured rats treated with EPO + MLT showed a trend toward fewer correction trials $(p=0.077)$, compared to vehicle-treated rats (Figure $4 \mathrm{~F}$ ). Further analyses of the maladaptive learning in the reversal paradigm consistent with a lack of cognitive flexibility, indicated a trend for improved performance during both perseveration and learning phases of the reversal paradigm. These results show that touchscreen testing can be used in PBI to distinguish complex behavior related to executive function and learning and that $\mathrm{EPO}+\mathrm{MLT}$ can at least partially reverse the reduced cognition present after prenatal injury.

\section{DISCUSSION}

In this investigation, we tested the efficacy of combined $\mathrm{EPO}+$ MLT for neurorepair of the deficits associated with CP using translatable outcome measures, with the goal of facilitating rapid transition to neonatal clinical trials. To begin, we capitalized on a preclinical platform and model of $\mathrm{CP}$ that accurately recapitulates the multi-faceted pathophysiology of early CNS injury, including an intact maternal-placental-fetal axis, and sustained deficits in adult animals in multiple functional domains. These investigations reflect recent clinical epidemiological progress that indicates most CP arises from prenatal injury and that only $12 \%$ of cases arise from intrapartum insults (7). Consistent with clinical data, the preclinical findings reported here reaffirm the concept that chorioamnionitis concomitant with placental insufficiency results in dynamic, multifactorial, and permanent changes to the CNS culminating in functional deficits in mature rats. Indeed, this prenatal insult causes significant chronic behavioral, social, executive function, and gait deficits in adult rats, similar to those observed in children with CP $(46,62,71)$. This model that incorporates intrauterine chorioamnionitis is one of very few preclinical models to induce persistent gait and neurocognitive deficits in the mature CNS $(40,70)$.

Mechanistically, compelling evidence suggests EPO and MLT have significant promise as potential synergistic interventions for neonates at high risk of CP. EPO and MLT have multiple over-lapping and complementary mechanisms of action. As developmentally regulated growth molecules, both EPO and MLT enhance neuronal and oligodendroglial survival and differentiation after CNS injury, suppress toxic cell death pathways, reduce free radicals, and mitigate inflammation from neonatal CNS infection (44-55). Unlike EPO, which is produced predominantly by the kidney and neural cells after birth (84), MLT is an endogenous indoleamine that is produced by the pineal gland postnatally and classically reported to regulate circadian rhythms. It is a direct antioxidant and free radical scavenger and also has indirect actions to increase the production of antioxidant enzymes including glutathione peroxidase (GP) and superoxide dismutase (SOD) (85). Notably, preterm infants with PBI, including those initiated in utero by choriomanionitis, are known to have reduced levels of GP and SOD in both the brain and lung (86).

The combination of EPO and MLT also has direct antiinflammatory and immunomodulatory properties integral to their beneficial effects. Impaired regulation of immune responses is detrimental to multiple pregnancy outcomes, including preterm birth. It is plausible that both EPO and MLT link maternal, placental, and fetal physiological cell signaling through mechanisms of entrainment and direct biological actions (87). Interestingly, MLT is synthesized in higher concentrations within the placenta than the pineal gland $(87,88)$. Specifically, cyto- and syncytiotrophoblasts from the placenta contain two enzymes, serotonin $\mathrm{N}$-acetyltransferase and $\mathrm{N}$-acetylserotonin methyltransferase, which metabolize serotonin to MLT. Once in the circulation, MLT can increase phagocytosis, antigen presentation, and exert antioxidant effects $(87,89)$. Indeed, both EPO and MLT are known to affect Th1/Th2 ratio, Th17, neutrophils, and microglia, major cellular mediators of chorioamnionitis and PBI $(87,90)$. Through separate signal transduction, CNS inflammation actually reduces innate CNS EPO and MLT production, thereby diminishing endogenous neurorepair (91). In this context, similar to exogenous EPO therapy, exogenous MLT administration after birth may supplement innate levels by the pineal gland and replace a MLT deficit arising from premature separation from placental sources and/or induced inflammation from intrauterine infection or injury.

Erythropoietin and MLT also promote the genesis, survival, and differentiation of neural cells in the developing and mature CNS and reduce calpain-mediated injury. Previously, we have shown that sustained excess calpain activity is an important mechanism of injury in the immature CNS $(45,47,48)$ and that extended EPO treatment mitigates calpain-mediated damage (48). Specifically, calpain degrades CNS molecules and proteins essential for the formation of cerebral circuits, including neurofilaments, myelin basic protein, and the potassium chloride cotransporter KCC2 (48). Therefore, through EPO and MLT together, it may be possible to cumulatively preserve more axon-myelin structural units, including those in major cerebral white matter and corticospinal tracts, by inhibiting detrimental protease expression, preserving structural connectivity, and restoring inhibitory neural networks. Indeed, it is through this action on structural and functional connectivity, neural conduction, and excitatory/inhibitory balance of fundamental circuitry that this combination of therapy likely improves motor and cognitive function into early adulthood (P90) following prenatal injury $(46-48,71)$.

Recently, it has been demonstrated that EPO has an additional novel mechanism in regulation of homeostatic plasticity and synaptic strength (92). Together, with previous reports on the modulation of inhibitory circuitry in brain regions key to higher order brain function and structural connectivity, this effect on synapses provides an additional novel molecular mechanism supporting the improvement in cognition and behavior shown here, and the normalization of the trajectory of brain development 
after perinatal injury $(47,66,71,72,92-94)$. Similarly, complimenting the EPOR distribution on glia, and neurons, and the importance of receptor/ligand balance in the developing brain (55), MLT receptors, MT1 and MT2, are present in regions of the brain that are important to cognition and memory, including the hippocampus and frontal cortex and are similarly regulated by endogenous MLT $(69,87,95,96)$. In rodents, several studies have reported improved social behavior, anxiolytic, antidepressant, and memory-facilitating effects of exogenous MLT related to modulation of essential neurotransmitters and their receptors, including GABAergic, dopaminergic, glutamatergic, cholinergic, and noradrenergic transmission (69, 97-100). Consistent with our data, studies in mice confirm a MLT-induced decrease in open field hyperlocomotion (69). Indeed, our data also matches prior studies demonstrating that MLT administration in similar dosing ranges reverses ketamine-induced deficits in social interaction and memory impairment (69). Significantly, these investigators found that mitigation of social deficits only occurred with dose-dependent, repeated administration of MLT. Interestingly, in our studies, the combination of EPO + MLT was able to reverse abnormal open field behavior, whereas EPO alone was not. This highlights that, in specific microenvironments, a combination of agents may be more effective than one agent alone, and through repair of white matter, synapses, structural connectivity, neural network efficiency, and multiple neurotransmitter systems, EPO and MLT together may additively improve multiple pillars of cognition and behavior.

This is the first time to our knowledge that touchscreen platforms have been used with preclinical models of CP and PBI. Given that many children with CP have sensorimotor and cognitive deficits, there is a need to study strategies that address both functional domains. Touchscreen assessment is a highly translatable outcome measure also utilized in human trials and the Cambridge Neuropsychological Test Automated Battery is regularly used for neuropsychological testing of children and adults $(76,80)$. Our results demonstrate that EPO + MLT partially mitigates deficits of cognition, specifically executive function and reversal learning. These data support the clinical literature showing that very preterm children and adolescents are at high risk for executive function deficits that only become apparent with increasing cognitive demands. Specifically, compared to healthy born peers, preterm adolescents scored significantly lower in the most demanding levels of working memory, planning, cognitive flexibility, and verbal fluency tasks, despite no group differences being detected at lowest demand levels (101).

We also found in utero injury influenced exploratory behavior in mature animals, with EPO + MLT normalizing excess center mobility and resting time in an open field. These data are consistent with prior studies demonstrating improvements in exploratory behavior and resting time with MLT treatment, consistent with normalization of disinhibition, hyperlocomotion, and depression-like behavior (102). Indeed, prior reports suggest that MLT exerts a long-term effect on striatal dopamine content by enhancing monoamine synthesis $(102,103)$. While that investigation was performed in older rats, it is possible that normalized monoamine system development might improve motor coordination and cognition. Similarly, MLT also acts as a
$5 \mathrm{HT}_{2 \mathrm{~A}}$ antagonist in the hippocampus, and through the regulation of 5HT release may also impact complex behaviors related to anxiety, behavioral inhibition, and locomotion $(102,104)$. Notably, children with CP often exhibit spasticity and difficulty with selective motor control. Selective motor control is regulated predominantly by descending serotonin pathways that innervate the lumbar spinal cord on E18 in rats (105), the same age as the prenatal injury used here. Importantly, signaling via $5 \mathrm{HT}_{2 \mathrm{~A}}$ upregulates spinal KCC2 levels (106). Serotonin signaling is also integral to cognitive flexibility (107). Thus, repairing myelination, axons, KCC2 levels and preserving homeostasis of serotonin signaling may be key mechanistic conversion points of EPO + MLT combination therapy and critical to minimizing spasticity, loss of selective motor control, and preserving cognition in children with $\mathrm{CP}$ from prematurity.

In conclusion, EPO + MLT are plausible targeted pharmacotherapies that specifically enhance neurorepair via novel and disease-specific molecular mechanisms. Receptor and non-receptor-mediated pathways underpin the multiple neuroprotective effects of MLT and EPO that include supporting mitochondrial function, and post-injury plasticity, and antioxidant, anti-apoptotic, and anti-inflammatory actions $(108,109)$. Together with normalization of social interaction, these data suggest a plausible treatment strategy to address multiple realms of cognition and behavior. In conjunction with data presented in this study, coupled with EPO and MLT's known safety profile, multiple beneficial mechanisms of action, ability to penetrate the brain and organelles, and ease of administration, EPO and MLT in combination merits thoughtful consideration of clinical trials for preterm infants with brain injury.

\section{ETHICS STATEMENT}

This study was carried out in accordance with the recommendations and approval of The Institutional Care and Use Committee (IACUC) at the University of New Mexico Health Sciences Center, Boston Children's Hospital, and Johns Hopkins University.

\section{AUTHOR CONTRIBUTIONS}

Conception and design: SR and LJ. Acquisition of data: LJ, AO, FC, TY, JK, GF, and AW. Analysis and interpretation of data: LJ, SR, and FN. Drafting the article: SR and LJ. Critically revising the article: all authors. Reviewed submitted version of manuscript: all authors. Study supervision: SR and LJ. SR's previous institution and location at the beginning of this study: Department of Neurosurgery, Boston Children's Hospital, Harvard Medical School, Boston MA.

\section{ACKNOWLEDGMENTS}

The authors are grateful to Jonathan Brigman, Ph.D. for his expertise with touchscreen testing and interpretation. We are also grateful for the funding provided by the Cerebral Palsy Alliance Research Foundation (PG4116 to SR, FN, and LJ), the Genise Goldenson Fund (to SR and LJ), and the American Heart Association (17SDG33670850 to LJ). 


\section{REFERENCES}

1. Jantzie LL, Scafidi J, Robinson S. Stem cells and cell-based therapies for cerebral palsy: a call for rigor. Pediatr Res (2018) 83(1-2):345-55. doi:10.1038/ pr.2017.233

2. Eunson P. Aetiology and epidemiology of cerebral palsy. Paediatr Child Health (2016) 26(9):367-72. doi:10.1016/j.paed.2016.04.011

3. Stoll BJ, Hansen NI, Bell EF, Walsh MC, Carlo WA, Shankaran S, et al. Trends in care practices, morbidity, and mortality of extremely preterm neonates, 1993-2012. JAMA (2015) 314(10):1039-51. doi:10.1001/jama.2015.10244

4. Saigal S, Doyle L. An overview of mortality and sequelae of preterm birth from infancy to adulthood. Lancet (2008) 371:261-9. doi:10.1016/ S0140-6736(08)60136-1

5. Nelson KB, Blair E. Prenatal factors in singletons with cerebral palsy born at or near term. N Engl J Med (2015) 373(10):946-53. doi:10.1056/ NEJMra1505261

6. Durkin MS. Socio-economic disparities and functional limitations of children with cerebral palsy. Dev Med Child Neurol (2016) 58(2):115. doi:10.1111/dmcn.12821

7. Pappas A, Korzeniewski SJ. Long-term cognitive outcomes of birth asphyxia and the contribution of identified perinatal asphyxia to cerebral palsy. Clin Perinatol (2016) 43(3):559-72. doi:10.1016/j.clp.2016.04.012

8. Galinsky R, Polglase GR, Hooper SB, Black MJ, Moss TJ. The consequences of chorioamnionitis: preterm birth and effects on development. J Pregnancy (2013) 2013:412831. doi:10.1155/2013/412831

9. Lahra MM, Beeby PJ, Jeffery HE. Maternal versus fetal inflammation and respiratory distress syndrome: a 10-year hospital cohort study. Arch Dis Child Fetal Neonatal Ed (2009) 94(1):F13-6. doi:10.1136/adc.2007.135889

10. Lahra MM, Jeffery HE. A fetal response to chorioamnionitis is associated with early survival after preterm birth. Am J Obstet Gynecol (2004) 190(1):147-51. doi:10.1016/j.ajog.2003.07.012

11. Redline RW. Inflammatory responses in the placenta and umbilical cord. Semin Fetal Neonatal Med (2006) 11(5):296-301. doi:10.1016/j. siny.2006.02.011

12. Redline RW. Disorders of placental circulation and the fetal brain. Clin Perinatol (2009) 36(3):549-59. doi:10.1016/j.clp.2009.06.003

13. Abdulkadir AA, Kimimasa T, Bell MJ, Macpherson TA, Keller BB, Yanowitz TD. Placental inflammation and fetal hemodynamics in a rat model of chorioamnionitis. Pediatr Res (2010) 68(6):513-8. doi:10.1203/ PDR.0b013e3181f851ed

14. Kaufmann P. Influence of ischemia and artificial perfusion on placental ultrastructure and morphometry. Contrib Gynecol Obstet (1985) 13:18-26.

15. Kumazaki K, Nakayama M, Sumida Y, Ozono K, Mushiake S, Suehara N, et al. Placental features in preterm infants with periventricular leukomalacia. Pediatrics (2002) 109(4):650-5. doi:10.1542/peds.109.4.650

16. Anblagan D, Pataky R, Evans MJ, Telford EJ, Serag A, Sparrow S, et al. Association between preterm brain injury and exposure to chorioamnionitis during fetal life. Sci Rep (2016) 6:37932. doi:10.1038/srep37932

17. Boardman JP, Craven C, Valappil S, Counsell SJ, Dyet LE, Rueckert D, et al. A common neonatal image phenotype predicts adverse neurodevelopmental outcome in children born preterm. Neuroimage (2010) 52(2):409-14. doi:10.1016/j.neuroimage.2010.04.261

18. Counsell SJ, Shen Y, Boardman JP, Larkman DJ, Kapellou O, Ward P, et al. Axial and radial diffusivity in preterm infants who have diffuse white matter changes on magnetic resonance imaging at term-equivalent age. Pediatrics (2006) 117(2):376-86. doi:10.1542/peds.2005-0820

19. Counsell SJ, Edwards AD, Chew AT, Anjari M, Dyet LE, Srinivasan L, et al. Specific relations between neurodevelopmental abilities and white matter microstructure in children born preterm. Brain (2008) 131(Pt 12):3201-8. doi:10.1093/brain/awn268

20. Rutherford MA, Pennock JM, Counsell SJ, Mercuri E, Cowan FM, Dubowitz LM, et al. Abnormal magnetic resonance signal in the internal capsule predicts poor neurodevelopmental outcome in infants with hypoxic-ischemic encephalopathy. Pediatrics (1998) 102(2 Pt 1):323-8. doi:10.1542/peds.102.2.323

21. Perez A, Ritter S, Brotschi B, Werner H, Caflisch J, Martin E, et al. Longterm neurodevelopmental outcome with hypoxic-ischemic encephalopathy. J Pediatr (2013) 163(2):454-9. doi:10.1016/j.jpeds.2013.02.003

22. Wu YW, Colford JM Jr. Chorioamnionitis as a risk factor for cerebral palsy: a meta-analysis. JAMA (2000) 284(11):1417-24. doi:10.1001/jama.284.11.1417
23. Wu YW, Escobar GJ, Grether JK, Croen LA, Greene JD, Newman TB. Chorioamnionitis and cerebral palsy in term and near-term infants. JAMA (2003) 290(20):2677-84. doi:10.1001/jama.290.20.2677

24. Torricelli M, Voltolini C, Conti N, Vellucci FL, Orlandini C, Bocchi C, et al. Histologic chorioamnionitis at term: implications for the progress of labor and neonatal wellbeing. J Matern Fetal Neonatal Med (2013) 26(2):188-92. doi:10.3109/14767058.2012.722724

25. Nath CA, Ananth CV, Smulian JC, Shen-Schwarz S, Kaminsky L; New Jersey-Placental Abruption Study Investigators. Histologic evidence of inflammation and risk of placental abruption. Am J Obstet Gynecol (2007) 197(3):e1-6. doi:10.1016/j.ajog.2007.06.012

26. Watterberg KL, Scott SM, Naeye RL. Chorioamnionitis, cortisol, and acute lung disease in very low birth weight infants. Pediatrics (1997) 99(2):E6. doi:10.1542/peds.99.2.e6

27. O'Shea TM, Allred EN, Kuban KC, Dammann O, Paneth N, Fichorova R, et al. Elevated concentrations of inflammation-related proteins in postnatal blood predict severe developmental delay at 2 years of age in extremely preterm infants. J Pediatr (2012) 160(3):395-401.e4. doi:10.1016/j.jpeds.2011. 08.069

28. O'Shea TM, Joseph RM, Kuban KC, Allred EN, Ware J, Coster T, et al. Elevated blood levels of inflammation-related proteins are associated with an attention problem at age 24 mo in extremely preterm infants. Pediatr Res (2014) 75(6):781-7. doi:10.1038/pr.2014.41

29. Dueck CC, Grynspan D, Eisenstat DD, Caces R, Rafay MF. Ischemic perinatal stroke secondary to chorioamnionitis: a histopathological case presentation. J Child Neurol (2009) 24(12):1557-60. doi:10.1177/0883073809341271

30. Wintermark P, Boyd T, Gregas MC, Labrecque M, Hansen A. Placental pathology in asphyxiated newborns meeting the criteria for therapeutic hypothermia. Am J Obstet Gynecol (2010) 203(6):e1-9. doi:10.1016/j. ajog.2010.08.024

31. Lee J, Kim JS, Park JW, Park CW, Park JS, Jun JK, et al. Chronic chorioamnionitis is the most common placental lesion in late preterm birth. Placenta (2013) 34(8):681-9. doi:10.1016/j.placenta.2013.04.014

32. Lee SM, Park JW, Kim BJ, Park CW, Park JS, Jun JK, et al. Acute histologic chorioamnionitis is a risk factor for adverse neonatal outcome in late preterm birth after preterm premature rupture of membranes. PLoS One (2013) 8(12):e79941. doi:10.1371/journal.pone.0079941

33. Conti N, Torricelli M, Voltolini C, Vannuccini S, Clifton VL, Bloise E, et al. Term histologic chorioamnionitis: a heterogeneous condition. Eur J Obstet Gynecol Reprod Biol (2015) 188:34-8. doi:10.1016/j.ejogrb.2015.02.034

34. Torricelli M, Voltolini C, Toti P, Vellucci FL, Conti N, Cannoni A, et al. Histologic chorioamnionitis: different histologic features at different gestational ages. J Matern Fetal Neonatal Med (2014) 27(9):910-3. doi:10.3109/1 4767058.2013.846313

35. Lee SM, Lee KA, Kim SM, Park CW, Yoon BH. The risk of intra-amniotic infection, inflammation and histologic chorioamnionitis in term pregnant women with intact membranes and labor. Placenta (2011) 32(7):516-21. doi:10.1016/j.placenta.2011.03.012

36. Redline RW, O'Riordan MA. Placental lesions associated with cerebral palsy and neurologic impairment following term birth. Arch Pathol Lab Med (2000) 124(12):1785-91. doi:10.1043/0003-9985(2000)124<1785: PLAWCP $>2.0 . \mathrm{CO} ; 2$

37. Lachapelle J, Chen M, Oskoui M, Ali N, Brown R, Wintermark P. Placental pathology in asphyxiated newborns treated with therapeutic hypothermia. J Neonatal Perinatal Med (2015) 8(1):33-40. doi:10.3233/NPM-15814068

38. Shevell A, Wintermark P, Benini R, Shevell M, Oskoui M. Chorioamnionitis and cerebral palsy: lessons from a patient registry. Eur J Paediatr Neurol (2014) 18(3):301-7. doi:10.1016/j.ejpn.2013.12.005

39. Edwards JM, Edwards LE, Swamy GK, Grotegut CA. Magnesium sulfate for neuroprotection in the setting of chorioamnionitis. J Matern Fetal Neonatal Med (2017) 31(9):1156-60. doi:10.1080/14767058.2017.1311312

40. Coq JO, Delcour M, Massicotte VS, Baud O, Barbe MF. Prenatal ischemia deteriorates white matter, brain organization, and function: implications for prematurity and cerebral palsy. Dev Med Child Neurol (2016) 58(Suppl 4):7-11. doi:10.1111/dmcn. 13040

41. Gonzalez FF, Ferriero DM. Therapeutics for neonatal brain injury. Pharmacol Ther (2008) 120(1):43-53. doi:10.1016/j.pharmthera.2008.07.003

42. Robertson NJ, Tan S, Groenendaal F, van Bel F, Juul SE, Bennet L, et al. Which neuroprotective agents are ready for bench to bedside translation 
in the newborn infant? J Pediatr (2012) 160(4):544-52.e4. doi:10.1016/j. jpeds.2011.12.052

43. Peters JU. Polypharmacology - foe or friend? J Med Chem (2013) 56(22):8955-71. doi:10.1021/jm400856t

44. Dominguez Rubio AP, Correa F, Aisemberg J, Dorfman D, Bariani MV, Rosenstein RE, et al. Maternal administration of melatonin exerts short- and long-term neuroprotective effects on the offspring from lipopolysaccharide-treated mice. J Pineal Res (2017) 63(4):e12439. doi:10.1111/jpi.12439

45. Robinson S, Winer JL, Berkner J, Chan LA, Denson JL, Maxwell JR, et al. Imaging and serum biomarkers reflecting the functional efficacy of extended erythropoietin treatment in rats following infantile traumatic brain injury. J Neurosur Pediatr (2016) 17(6):739-55. doi:10.3171/2015.10.PEDS15554

46. Robinson S, Corbett CJ, Winer JL, Chan LAS, Maxwell JR, Anstine CV, et al. Neonatal erythropoietin mitigates impaired gait, social interaction and diffusion tensor imaging abnormalities in a rat model of prenatal brain injury. Exp Neurol (2017) 302:1-13. doi:10.1016/j.expneurol.2017.12.010

47. Jantzie LL, Getsy PM, Firl DJ, Wilson CG, Miller RH, Robinson S. Erythropoietin attenuates loss of potassium chloride co-transporters following prenatal brain injury. Mol Cell Neurosci (2014) 61:152-62. doi:10.1016/j. men.2014.06.009

48. Jantzie LL, Winer JL, Corbett CJ, Robinson S. Erythropoietin modulates cerebral and serum degradation products from excess calpain activation following prenatal hypoxia-ischemia. Dev Neurosci (2016) 38(1):15-26. doi:10.1159/000441024

49. Samantaray S, Sribnick EA, Das A, Knaryan VH, Matzelle DD, Yallapragada AV, et al. Melatonin attenuates calpain upregulation, axonal damage and neuronal death in spinal cord injury in rats. J Pineal Res (2008) 44(4):348-57. doi:10.1111/j.1600-079X.2007.00534.x

50. Zhao H, Wang R, Wu X, Liang J, Qi Z, Liu X, et al. Erythropoietin delivered via intra-arterial infusion reduces endoplasmic reticulum stress in brain microvessels of rats following cerebral ischemia and reperfusion. J Neuroimmune Pharmacol (2015) 10(1):153-61. doi:10.1007/ s11481-014-9571-z

51. Lu J, Dai QM, Ma GS, Zhu YH, Chen B, Li B, et al. Erythropoietin attenuates cardiac dysfunction in rats by inhibiting endoplasmic reticulum stress-induced diabetic cardiomyopathy. Cardiovasc Drugs Ther (2017) 31(4):367-79. doi:10.1007/s10557-017-6742-1

52. Carloni S, Albertini MC, Galluzzi L, Buonocore G, Proietti F, Balduini W. Melatonin reduces endoplasmic reticulum stress and preserves sirtuin 1 expression in neuronal cells of newborn rats after hypoxia-ischemia. J Pineal Res (2014) 57(2):192-9. doi:10.1111/jpi.12156

53. Fernandez A, Ordonez R, Reiter RJ, Gonzalez-Gallego J, Mauriz JL. Melatonin and endoplasmic reticulum stress: relation to autophagy and apoptosis. J Pineal Res (2015) 59(3):292-307. doi:10.1111/jpi.12264

54. Jantzie LL, Miller RH, Robinson S. Erythropoietin signaling promotes oligodendrocyte development following prenatal systemic hypoxic-ischemic brain injury. Pediatr Res (2013) 74(6):658-67. doi:10.1038/pr.2013.155

55. Mazur M, Miller RH, Robinson S. Postnatal erythropoietin treatment mitigates neural cell loss after systemic prenatal hypoxic-ischemic injury. J Neurosurg Pediatr (2010) 6(3):206-21. doi:10.3171/2010.5.PEDS1032

56. Castro A, Raver C, Li Y, Uddin O, Rubin D, Ji Y, et al. Cortical regulation of nociception of the trigeminal nucleus caudalis. JNeurosci (2017) 37(47):11431-40. doi:10.1523/JNEUROSCI.3897-16.2017

57. Landis SC, Amara SG, Asadullah K, Austin CP, Blumenstein R, Bradley EW, et al. A call for transparent reporting to optimize the predictive value of preclinical research. Nature (2012) 490(7419):187-91. doi:10.1038/ nature 11556

58. Kilkenny C, Parsons N, Kadyszewski E, Festing MF, Cuthill IC, Fry D, et al. Survey of the quality of experimental design, statistical analysis and reporting of research using animals. PLoS One (2009) 4(11):e7824. doi:10.1371/journal. pone. 0007824

59. Badawi N, Kurinczuk JJ, Keogh JM, Alessandri LM, O’Sullivan F, Burton $\mathrm{PR}$, et al. Intrapartum risk factors for newborn encephalopathy: the western Australian case-control study. BMJ (1998) 317(7172):1554-8. doi:10.1136/ bmj.317.7172.1554

60. Bastek JA, Brown AG, Anton L, Srinivas SK, D’Addio A, Elovitz MA. Biomarkers of inflammation and placental dysfunction are associated with subsequent preterm birth. J Matern Fetal Neonatal Med (2011) 24(4):600-5. doi:10.3109/14767058.2010.511340
61. Redline RW. Correlation of placental pathology with perinatal brain injury. Surg Pathol Clin (2013) 6(1):153-80. doi:10.1016/j.path.2012.11.005

62. Jantzie LL, Corbett CJ, Berglass J, Firl DJ, Flores J, Mannix R, et al. Complex pattern of interaction between in utero hypoxia-ischemia and intra-amniotic inflammation disrupts brain development and motor function. J Neuroinflammation (2014) 11:131. doi:10.1186/1742-2094-11-131

63. Jantzie LL, Winer JL, Maxwell JR, Chan LA, Robinson S. Modeling encephalopathy of prematurity using prenatal hypoxia-ischemia with intra-amniotic lipopolysaccharide in rats. J Vis $\operatorname{Exp}$ (2015) (105):e53196. doi:10.3791/53196

64. Maxwell JR, Denson JL, Joste NE, Robinson S, Jantzie LL. Combined in utero hypoxia-ischemia and lipopolysaccharide administration in rats induces chorioamnionitis and a fetal inflammatory response syndrome. Placenta (2015) 36(12):1378-84. doi:10.1016/j.placenta.2015.10.009

65. Yellowhair TR, Noor S, Maxwell JR, Anstine CV, Oppong AY, Robinson S, et al. Preclinical chorioamnionitis dysregulates CXCL1/CXCR2 signaling throughout the placental-fetal-brain axis. Exp Neurol (2018) 301(Pt B):110-9. doi:10.1016/j.expneurol.2017.11.002

66. Mulkey SB, Ramakrishnaiah RH, McKinstry RC, Chang T, Mathur AM, Mayock DE, et al. Erythropoietin and brain magnetic resonance imaging findings in hypoxic-ischemic encephalopathy: volume of acute brain injury and 1-year neurodevelopmental outcome. J Pediatr (2017) 186:196-9. doi:10.1016/j.jpeds.2017.03.053

67. Miskowiak KW, Vinberg M, Glerup L, Paulson OB, Knudsen GM, Ehrenreich $\mathrm{H}$, et al. Neural correlates of improved executive function following erythropoietin treatment in mood disorders. Psychol Med (2016) 46(8):1679-91. doi:10.1017/S0033291716000209

68. Leuchter RH, Gui L, Poncet A, Hagmann C, Lodygensky GA, Martin E, et al. Association between early administration of high-dose erythropoietin in preterm infants and brain MRI abnormality at term-equivalent age. JAMA (2014) 312(8):817-24. doi:10.1001/jama.2014.9645

69. Onaolapo AY, Aina OA, Onaolapo OJ. Melatonin attenuates behavioural deficits and reduces brain oxidative stress in a rodent model of schizophrenia. Biomed Pharmacother (2017) 92:373-83. doi:10.1016/j.biopha.2017. 05.094

70. Jantzie LL, Robinson S. Preclinical models of encephalopathy of prematurity. Dev Neurosci (2015) 37(4-5):277-88. doi:10.1159/000371721

71. Jantzie LL, Corbett CJ, Firl DJ, Robinson S. Postnatal erythropoietin mitigates impaired cerebral cortical development following subplate loss from prenatal hypoxia-ischemia. Cereb Cortex (2015) 25(9):2683-95. doi:10.1093/cercor/ bhu066

72. Jantzie LL, Getsy P, Denson JL, Firl DJ, Wilson CG, Robinson S. Prenatal hypoxia-ischemia induces potassium chloride cotransporter 2 loss and abnormalities in inhibitory tone. Front Cell Neurosci (2015) 9:347. doi:10.3389/fncel.2015.00347

73. Foley KA, MacFabe DF, Vaz A, Ossenkopp KP, Kavaliers M. Sexually dimorphic effects of prenatal exposure to propionic acid and lipopolysaccharide on social behavior in neonatal, adolescent, and adult rats: implications for autism spectrum disorders. Int J Dev Neurosci (2014) 39:68-78. doi:10.1016/j. ijdevneu.2014.04.001

74. Zugno AI, Canever L, Heylmann AS, Wessler PG, Steckert A, Mastella GA, et al. Effect of folic acid on oxidative stress and behavioral changes in the animal model of schizophrenia induced by ketamine. J Psychiatr Res (2016) 81:23-35. doi:10.1016/j.jpsychires.2016.06.013

75. Schneider T, Przewlocki R. Behavioral alterations in rats prenatally exposed to valproic acid: animal model of autism. Neuropsychopharmacology (2005) 30(1):80-9. doi:10.1038/sj.npp.1300518

76. Bussey TJ, Holmes A, Lyon L, Mar AC, McAllister KA, Nithianantharajah J, et al. New translational assays for preclinical modelling of cognition in schizophrenia: the touchscreen testing method for mice and rats. Neuropharmacology (2012) 62(3):1191-203. doi:10.1016/j.neuropharm.2011.04.011

77. Horner AE, Heath CJ, Hvoslef-Eide M, Kent BA, Kim CH, Nilsson SR, et al. The touchscreen operant platform for testing learning and memory in rats and mice. Nat Protoc (2013) 8(10):1961-84. doi:10.1038/nprot. 2013.122

78. Mar AC, Horner AE, Nilsson SR, Alsio J, Kent BA, Kim CH, et al. The touchscreen operant platform for assessing executive function in rats and mice. Nat Protoc (2013) 8(10):1985-2005. doi:10.1038/nprot.2013.123

79. Oomen CA, Hvoslef-Eide M, Heath CJ, Mar AC, Horner AE, Bussey TJ, et al. The touchscreen operant platform for testing working memory and pattern 
separation in rats and mice. Nat Protoc (2013) 8(10):2006-21. doi:10.1038/ nprot.2013.124

80. Bussey TJ, Padain TL, Skillings EA, Winters BD, Morton AJ, Saksida LM. The touchscreen cognitive testing method for rodents: how to get the best out of your rat. Learn Mem (2008) 15(7):516-23. doi:10.1101/lm.987808

81. Marquardt K, Sigdel R, Caldwell K, Brigman JL. Prenatal ethanol exposure impairs executive function in mice into adulthood. Alcohol Clin Exp Res (2014) 38(12):2962-8. doi:10.1111/acer.12577

82. Brigman JL, Daut RA, Wright T, Gunduz-Cinar O, Graybeal C, Davis MI, et al. GluN2B in corticostriatal circuits governs choice learning and choice shifting. Nat Neurosci (2013) 16(8):1101-10. doi:10.1038/nn.3457

83. Brigman JL, Mathur P, Harvey-White J, Izquierdo A, Saksida LM, Bussey TJ, et al. Pharmacological or genetic inactivation of the serotonin transporter improves reversal learning in mice. Cereb Cortex (2010) 20(8):1955-63. doi:10.1093/cercor/bhp266

84. Chavez JC, Baranova O, Lin J, Pichiule P. The transcriptional activator hypoxia inducible factor 2 (HIF-2/EPAS-1) regulates the oxygen-dependent expression of erythropoietin in cortical astrocytes. J Neurosci (2006) 26(37):9471-81. doi:10.1523/JNEUROSCI.2838-06.2006

85. Balduini W, Carloni S, Perrone S, Bertrando S, Tataranno ML, Negro S, et al. The use of melatonin in hypoxic-ischemic brain damage: an experimental study. J Matern Fetal Neonatal Med (2012) 25(Suppl 1):119-24. doi:10.3109 /14767058.2012.663232

86. Pitkänen OM, Hallman M. Evidence for increased oxidative stress in preterm infants eventually developing chronic lung disease. Semin Neonatol (1998) 3(3):199-205. doi:10.1016/S1084-2756(98)80005-5

87. Man GCW, Zhang T, Chen X, Wang J, Wu F, Liu Y, et al. The regulations and role of circadian clock and melatonin in uterine receptivity and pregnancy-an immunological perspective. Am J Reprod Immunol (2017):e12715 78(2). doi:10.1111/aji.12715

88. Okatani Y, Okamoto K, Hayashi K, Wakatsuki A, Tamura S, Sagara Y. Maternal-fetal transfer of melatonin in pregnant women near term. J Pineal Res (1998) 25(3):129-34. doi:10.1111/j.1600-079X.1998.tb00550.x

89. Szczepanik M. Melatonin and its influence on immune system. JPhysiol Pharmacol (2007) 58(Suppl 6):115-24.

90. Kallapur SG, Presicce P, Rueda CM, Jobe AH, Chougnet CA. Fetal immune response to chorioamnionitis. Semin Reprod Med (2014) 32(1):56-67. doi:10.1055/s-0033-1361823

91. Herman AP, Bochenek J, Krol K, Krawczynska A, Antushevich H, Pawlina B, et al. Central interleukin-1beta suppresses the nocturnal secretion of melatonin. Mediators Inflamm (2016) 2016:2589483. doi:10.1155/2016/2589483

92. Dias RB, Rodrigues TM, Rombo DM, Ribeiro FF, Rodrigues J, McGarvey J, et al. Erythropoietin induces homeostatic plasticity at hippocampal synapses. Cereb Cortex (2017):1-15. doi:10.1093/cercor/bhx159

93. O'Gorman RL, Bucher HU, Held U, Koller BM, Huppi PS, Hagmann CF, et al. Tract-based spatial statistics to assess the neuroprotective effect of early erythropoietin on white matter development in preterm infants. Brain J Neurol (2015) 138(Pt 2):388-97. doi:10.1093/brain/awu363

94. Ohls RK, Kamath-Rayne BD, Christensen RD, Wiedmeier SE, Rosenberg A, Fuller J, et al. Cognitive outcomes of preterm infants randomized to darbepoetin, erythropoietin, or placebo. Pediatrics (2014) 133(6):1023-30. doi:10.1542/peds.2013-4307

95. Venegas C, GarciaJA,Escames G, OrtizF, LopezA, DoerrierC, etal.Extrapineal melatonin: analysis of its subcellular distribution and daily fluctuations. J Pineal Res (2012) 52(2):217-27. doi:10.1111/j.1600-079X.2011.00931.x

96. Ekmekcioglu C. Melatonin receptors in humans: biological role and clinical relevance. Biomed Pharmacother (2006) 60(3):97-108. doi:10.1016/j. biopha.2006.01.002

97. Binfare RW, Mantovani M, Budni J, Santos AR, Rodrigues AL. Involvement of dopamine receptors in the antidepressant-like effect of melatonin in the tail suspension test. Eur J Pharmacol (2010) 638(1-3):78-83. doi:10.1016/j. ejphar.2010.04.011

98. Mantovani M, Kaster MP, Pertile R, Calixto JB, Rodrigues AL, Santos AR. Mechanisms involved in the antinociception caused by melatonin in mice. JPineal Res (2006) 41(4):382-9. doi:10.1111/j.1600-079X.2006. 00380.x

99. Mantovani M, Pertile R, Calixto JB, Santos AR, Rodrigues AL. Melatonin exerts an antidepressant-like effect in the tail suspension test in mice: evidence for involvement of $\mathrm{N}$-methyl-D-aspartate receptors and the L-argininenitric oxide pathway. Neurosci Lett (2003) 343(1):1-4. doi:10.1016/S03043940(03)00306-9

100. Berkiks I, Benmhammed H, Mesfioui A, Ouichou A, El Hasnaoui A, Mouden $\mathrm{S}$, et al. Postnatal melatonin treatment protects against affective disorders induced by early-life immune stimulation by reducing the microglia cell activation and oxidative stress. Int J Neurosci (2018) 128(6):495-504. doi:10. 1080/00207454.2017.1398156

101. Wehrle FM, Kaufmann L, Benz LD, Huber R, O’Gorman RL, Latal B, et al. Very preterm adolescents show impaired performance with increasing demands in executive function tasks. Early Hum Dev (2016) 92:37-43. doi:10.1016/j.earlhumdev.2015.10.021

102. Spasojevic N, Stefanovic B, Jovanovic P, Dronjak S. Anxiety and hyperlocomotion induced by chronic unpredictable mild stress can be moderated with melatonin treatment. Folia Biol (Praha) (2016) 62(6):250-7.

103. Esteban S, Garau C, Aparicio S, Moranta D, Barcelo P, Fiol MA, et al. Chronic melatonin treatment and its precursor L-tryptophan improve the monoaminergic neurotransmission and related behavior in the aged rat brain. J Pineal $\operatorname{Res}(2010)$ 48(2):170-7. doi:10.1111/j.1600-079X.2009.00741.x

104. Monnet FP. Melatonin modulates [3h]serotonin release in the rat hippocampus: effects of circadian rhythm. J Neuroendocrinol (2002) 14(3):194-9. doi:10.1046/j.0007-1331.2001.00761.x

105. Branchereau P, Morin D, Bonnot A, Ballion B, Chapron J, Viala D. Development of lumbar rhythmic networks: from embryonic to neonate locomotor-like patterns in the mouse. Brain Res Bull (2000) 53(5):711-8. doi:10.1016/S0361-9230(00)00403-2

106. Bos R, Sadlaoud K, Boulenguez P, Buttigieg D, Liabeuf S, Brocard C, et al. Activation of 5-HT2A receptors upregulates the function of the neuronal K-Cl cotransporter KCC2. Proc Natl Acad Sci U S A (2013) 110(1):348-53. doi:10.1073/pnas. 1213680110

107. Waltz JA. The neural underpinnings of cognitive flexibility and their disruption in psychotic illness. Neuroscience (2017) 345:203-17. doi:10.1016/j. neuroscience.2016.06.005

108. Robertson NJ, Faulkner S, Fleiss B, Bainbridge A, Andorka C, Price D, et al. Melatonin augments hypothermic neuroprotection in a perinatal asphyxia model. Brain (2013) 136(Pt 1):90-105. doi:10.1093/brain/aws285

109. Husson I, Mesples B, Bac P, Vamecq J, Evrard P, Gressens P. Melatoninergic neuroprotection of the murine periventricular white matter against neonatal excitotoxic challenge. Ann Neurol (2002) 51(1):82-92. doi:10.1002/ ana. 10072

Conflict of Interest Statement: The authors declare that the research was conducted in the absence of any commercial or financial relationships that could be construed as a potential conflict of interest.

Copyright (c) 2018 Jantzie, Oppong, Conteh, Yellowhair, Kim, Fink, Wolin, Northington and Robinson. This is an open-access article distributed under the terms of the Creative Commons Attribution License (CC BY). The use, distribution or reproduction in other forums is permitted, provided the original author(s) and the copyright owner are credited and that the original publication in this journal is cited, in accordance with accepted academic practice. No use, distribution or reproduction is permitted which does not comply with these terms. 